\title{
Reframing motivation of modern leaders in investment and construction sectors in focus of organizational management
}

\author{
Larisa Vlasenko $^{1, *}$ and Irina Ivanova ${ }^{2}$ \\ ${ }^{1}$ Moscow State University of Civil Engineering, Yaroslavskoe shosse, 26, Moscow, 129337, Russia a \\ ${ }^{2}$ Financial University under the Government of the Russian Federation, Leningradsky pr. 49, \\ Moscow, 125993, Russia
}

\begin{abstract}
This article actualizes identification of both internal and external motivating factors of modern executives working in investment and construction sectors that directly influence their choice of behavior patterns and professional performance. Classical approaches to executives' personal motivation may change their attitude to work, however, the overall environment and internal transformations necessitate the use of reframing technologies that enable more efficient motivating mechanisms and systems. This article includes data of research participated by top executives of an investment and construction holding. The study covered a group of both external and internal motivating factors. The analysis results show that the motives rated by their significance level are a valid basis for selecting the most preferable management methods to be applied by experts holding senior positions in an organization.
\end{abstract}

\section{Introduction}

Ensuring efficient functioning of an organization is associated with activation of the personnel's internal reserve. Motivation makes a person adjust his/her behavior with consideration for his/her expectations; further on such a person would manage his/her behavior keeping in view the result. Thus, motivation makes a person pursue his/her personal, group or organizational goals [5]. It is generally known that motivational impact upon a person is only efficient in cases when such person has some specific needs. Actualizing and activating needs by using external and internal motivating factors will drive the desired behavior of an employee. In this regard, it is important to mention that "an individuum's actions may be efficiently controlled through motivation whenever the management object is in active pursuit of filling his/her needs by choosing specific behavior patterns" [4]. Identifying motivational attitudes of employees through the modern HR management techniques enables programs that match to the best extent the organizational environment and that aim at increasing the personnel's work satisfaction degree as well as the personnel's fidelity to the organizational environment; this makes it possible to apply the most impartial assessment and incentive methods [6].

\footnotetext{
*Corresponding author: vllv@inbox.ru
} 
Classical approaches to methods of motivating professional activities make the employees change their attitude to increasing their performance. However, the present-day stage of social development involves a broader view of motivational system and its impact on employees' performance which is driven by changes in the society, in its development level, in the significance of the most important human values and priorities; besides, such a view comprises the modern economic objectives and takes into account scientific and technical achievements.

It should be noticed that the internal needs of a management object may be activated, his/her internal motivation may be formed, his/her needs may be prioritized, and activities goals may be transformed through the impact by the management subject upon the external environmental factors. This suggests that the rating of needs is being constantly updated. In this connection, the use of reframing technology proposed by Richard Bandler and John Grinder in the 1980s [1] becomes topical. Reframing is a method to have a broader view of different processes and events through rethinking or rewording the well-established view by searching positive aspects of the situation or changing the perception thereof. Reframing technology enables a more impartial assessment of motivation processes status within the organizations as well as developing the motivation programs that match the organizational environment to the best extent. The most important thing about the organization is the motivation of its senior executives as their behavior model determines the managerial vector aimed at creating the in-house motivational mechanisms.

\section{Literature Review}

Let us take a view on the history of scientific theories of personnel management that appeared in the late $19^{\text {th }}$ century and were actively improved throughout the $20^{\text {th }}$ century and recently in the $21^{\text {st }}$ century. These theories thus formed a new paradigm of academic knowledge on management system.

As a result of more complicated working processes, new technologies, and scaling-up of production in various sectors, a new system of division of labor appeared and the view of the management object was changed. According to the classical management theories (like those developed by Frederick W. Taylor, Henri Fayol, Max Weber, Harrington Emerson and others), the main administrative impact is to be aimed at production technology, its efficiency and working environment; these theories say that executives have to exert tight control and ensure discipline at the workplace. Whereas the theories of human relations (like those developed by Elton Mayo, Robert Blake, Chris Argyris and others) and the theories of human resources (like those developed by Abraham Maslow, Frederick Herzberg, and Douglas McGregor) emphasize the importance of a human person and personal self-reliance stating that labor motivation has to be boosted and that people may manage their own motivation.

The classical motivation theories divide the needs into two groups, i.e. substantial needs and processual needs. This inextricable connection between the motivation and the human needs was described by Abraham Maslow, Clayton Alderfer, Frederick Herzberg, Sheila Ritchie, Peter Martin and many others. Thus, for example, Abraham Maslow, the author of a famous motivation theory, states that human motivations are driven by a 'pyramid of needs' that may be used to identify the motivations of employees at different levels and in different scopes of activities [7].

Every person tends to relax tensions that are manifested as agitation and anxiety whenever such a person feels he/she has a demand (that may be unconscious) to fill a certain need (either biological or social) [11]. The science of management says there are two main types of motivation, i.e. external motivation and internal motivation [8]. Internal (intrinsic) motivation is related to the contents of the work, its importance and significance for the person. This 
is a goal in itself, and not a kind of means for achieving another goal. External (extrinsic) motivation is driven by circumstances being external for the subject. This kind of motivation is firstly driven by awards, incentives, penalties and other types of external stimulation that initiate and direct the desirable behavior or put a stopper to the undesirable behavior.

\section{Research Objectives and Methods for Studying the Problem}

A research was conducted involving experts in investment and construction sectors who hold senior positions with a view to identify the most topical motivations that prevail with the modern executives being the management subjects as well as to trace their impact upon the rating of motivating factors of the management object that would influence the choice of preferable job motivation methods in the modern organizations.

The research on forces that drive leaders was based on the ' 12 Factors of Motivation' test developed by Sheila Ritchie and Peter Martin to identify the motivation factors that are highly rated by the employee being his/her best choice as well as the motivation factors that are of low significance for such an employee [9]. This test comprises twelve main needs of an employee that may be used as motivators in a team at work. An individual motivation profile (comprising different types of motivation factors, both internal and external) is created to identify personal combination of the most and the least important motivators for a specific person.

\section{Research Results}

Let us specify the contents of the factors included in the test to boost the information value of its results. The external motivation factors include high wages and material incentives (money); acknowledgements; power and influence (status); structuring. Internal motivation factors include physical working conditions (health); social contacts (need to communicate with the others); interrelations; pursuit of achievements (personal growth); interesting and useful work (the need of being useful); diversity and changes (curiosity); creativity (ideas, creative approach); self-improvement. While studying the needs of leaders, we identified the needs that act as motivators for leaders in a particular organization. The results were used as basis for creating a motivation profile for the group that comprises two sets of motivating factors [2].

The highest rated internal motivations include interesting and useful work (the need for meaningful and valuable work that is also of value for the community) and selfimprovement (the need for self-improvement, personal growth and development; the desire for self-sufficiency and independence). To our mind, this is hardly surprising. Indeed, today we see more activities aimed at searching for creative managerial solutions as development of construction sector is now of a nation-wide priority. Construction professionals feel that they are of high demand and social value. These factors add a special meaning to their work which is also supported by the organization thus driving the motivation. In terms of internal motivations set, the lowest priority factors include interrelations (the need for a closer contact with the others, long-term stable relationship with few colleagues) and creative approach (this indicator shows a trend to demonstrate keenness, curiosity and original way of thinking). Having put these indicators to analysis, one may conclude that low need in interrelations is a sign of poor social integration and lack of social graces. Relations within the team are a set of formal social roles that are typical mostly for this organization. Such roles indicate the degree of proximity between the team members. To our mind, an important reason giving rise to such a situation is the gender composition of the top 
management (top executives are mostly of male gender). Creative approach is even a weaker motivation driver. This situation is quite understandable, as construction by itself exerts high professional skills, good organization, high degree of responsibility and scrupulosity. As construction involves highly hazardous activities, all the actions are toughly regulated by organizational standards, requirements and safety procedures. The executives must comply with these.

While studying the external factors, we noted that the first choice of executives was the factor of high wages and material incentives (the need to have a well-paid job or job offering an attractive set of benefits and bonuses). This is another fact in support of the trend identified by psychologists. This trend shows that the less a person earns, the more importance he/she attaches to material remuneration, to the amount of his/her economic reward. The need for structuring (the need to decrease uncertainty and set a number of working rules and regulations as well as to receive a performance feedback) is an important aspect of human life, as this need shows the stress or anxiety degree that may increase or decrease whenever a person incurs serious changes in his/her personal or professional life. According to Sheila Ritchie and Peter Martin, this need may vary with time or subject to environment changes, i.e. in situations of uncertainty and changes this degree increases and during the times of stability this degree decreases [9]. This is a factor showing the stability degree within the organization and, consequently, the stability degree of its personnel.

The lowest rating in this set of factors was assigned to power and influence (this indicates the degree of competitive aggressiveness and implies comparing oneself to the other people and influencing such other people). To our mind, this may be due to the specifics of organizational activities in the construction sector.

\section{Conclusions}

General review of the top executives' priorities enabled us to note that the two main motivating factors for the professionals holding senior positions in investment and construction sectors are high earnings, material incentives as well as interesting and useful work. Top executives of the organization are stable and do not tend to change anything, they are ready to work and accept the working conditions offered to them by the organization, such top executives do not need to be in close contact with their colleagues, but they have an expressed need for self-improvement. The pursuance of self-improvement may further become the most important factor while searching a new job with high salary and material incentives. These executives do their best to link their personal ambitions with the organizational goals; they acknowledge that the need for improvement is of high importance to them, they act in a cautious and meticulous way while weighing up the pros and cons before assuming any financial risk [10]. Thus, we must note that the external motivation factor of 'high wages and material incentives' is of high priority to most of the executives. Whenever the top executives are driven by the external motivations, doubts arise in regard to efficiency of their impact upon the management object with the view to generate factors of internal motivation.

By applying the three groups of work motivation methods (organizational/administrative, economic and social/psychological) we can combine these with the motivation drivers that were rated in the course of our study. As a result, organizational/administrative methods (that include motivation drivers like interesting and useful work, structuring, self-improvement, pursuit of achievements, physical working conditions, creative approach and power within the team) proved to be more important for increasing motivation of the top executives who were part of the group in terms of the multi-aspect significant motivating factors. It is more feasible to include this motivation vector in the motivation programs. While managing this team, it is also feasible to apply 
economic motivation methods as motivation factors like high wages and material incentives are also within the actualization area for this group of respondents. The areas of concern include social/psychological motivation drivers that include factors like acknowledgements, social contacts, diversity, changes, and interrelations that are less efficient. The reasons making these motivation drivers less efficient include without limitation the fact that these are rarely applied within the organization.

The obtained data combined with the motivating factors that proved to be the most essential for the top executives suggest a conclusion that this organization should consider different approaches to motivation subject which depends upon the strategy it chooses, its current status, and its development stage. This would allow more flexible management solutions in terms of boosting the personnel performance.

Considering the issues covered by this research, the authors have prepared their reports for the International research-to-practice conferences as well as a number of research articles $[2,3,5]$.

\section{References}

1. R. Bandler, J. Grinder, Reframing: Neuro-Linguistic Programming and the Transformation of Meaning (1982)

2. L.V. Vlasenko, Yu.S. Prokhorova, Economics and Entrepreneurship 9(50), 824-829 (2014)

3. L.V. Vlasenko, I.P. Pryadko, Budgeting and Contractual Practices in Construction Sector 2, 22-26 (2016)

4. G.P. Gagarinskaya, Methodological Aspects of Managing the Work Motivation within an Industrial Enterprise, Personnel Management in Russia: History and Modern State (INFRA-M, Moscow, 2013)

5. I.A. Ivanova, Further Development of Works by E.A. Klimov, Materials of International Research-to-Practice Conference (Moscow, OOO Akropol, 2016)

6. I.A. Ivanova, Vestnik MGSU Scientific and Engineering Journal for Construction and Architecture 6, 522-527 (2011)

7. A. Maslow, Motivation and Personality (1952)

8. M.H. Mescon, Basics of Management, Management (1988)

9. Sh. Ritchie, P. Martin, Motivation Management (1999).

10. N.V. Samoukina, The Issue of Personnel Motivation, Personnel Management 7, 62-66 (2004)

11. R.A. Emmons, The Psychology of Ultimate Concerns: Motivation and Spirituality in Personality (1999) 